\title{
An Investigation on Parents' Satisfaction Evaluation on the Policies of Preschool Education in West China
}

\author{
Weihai Liao1,2, Xiaoping Yang1 \\ ${ }^{1}$ Department of Educational Science, Southwest University, Chongqing, China \\ ${ }^{2}$ Department of Teachers' Training, Guizhou University of Engineering Science, Bijie, China \\ Email: Iweihai@126.com, xpyangmail@126.com
}

Received 25 June 2015; accepted 24 July 2015; published 27 July 2015

Copyright (C) 2015 by authors and Scientific Research Publishing Inc.

This work is licensed under the Creative Commons Attribution International License (CC BY). http://creativecommons.org/licenses/by/4.0/

(c) (i) Open Access

\begin{abstract}
Basically popularizing preschool education is one of the most important duties for the government in mainland China in 2010-2020, but governments at all levels in West China are facing many challenges: difficult admission, expensive admission and low quality of preschool. Shaanxi Province was selected as a sample to look into these problems from the viewing angle of parents. 1980 parents from 66 public and private kindergartens in Shaanxi Province were investigated by using questionnaires, whose reliability and validity were tested. The results show that as a whole, parents are more satisfactory with the progress of popularization of preschool education in West China. The problem about difficult admission of preschool has been eased. Much progress has been made in solving the problem about expensive admission. Quality of preschool has been improved significantly. According to the parents' needs, wishes and expectations and the actual situation of West China, on the future policy formulation and implementation, Chinese Central Government and governments at all levels in West China should focus on expanding preschool education resources, adjusting the structure of private kindergartens and public kindergartens, improving the fund input mechanism, advancing the quality of kindergartens and enhancing homekindergarten cooperation.
\end{abstract}

\section{Keywords}

Parents, Difficult Admission, Expensive Admission, Quality of Preschool, Policy

\section{Introduction}

Basically popularizing the preschool education is one of the most important responsibilities for the government

How to cite this paper: Liao, W. H., \& Yang, X. P. (2015). An Investigation on Parents' Satisfaction Evaluation on the Policies of Preschool Education in West China. Creative Education, 6, 1407-1415. http://dx.doi.org/10.4236/ce.2015.612141 
in mainland China in 2010-2020 (Chinas State Council, 2010). In the process of basically popularizing the preschool education, due to the backward economy, governments at all levels in West China are facing severe challenges: difficult admission, expensive admission and low quality of preschool. In order to boost the development of preschool education in West China, a law named The Several Opinions on Preschool Education Development under the State Council was enacted in November 2010, and special funds were set up to help West China to solve problems about difficult admission and low quality of preschool. Chinese Ministry of Education declared in February 2014 that Chinas Central Finance would continuously increase input to support West China to popularize preschool education and solve problems about difficult admission, expensive admission and low quality of preschool. In November 2014, Chinese announced to implement the law named The Second Phase of the Three Years of Preschool Education Plan of Action to help West China to solve the above problems.

\section{Literature Review}

Chinese Central Government and governments at all levels in West China published a series of laws and regulations and adopted many measures to popularize preschool education, but hotspot issues in West China are still not well solved. Problems, such as low popularization rates of preschool education, low quality of preschool, insufficient funds (Hu, 2011; Jiang, 2013), low-status teachers and bad wages (Xia, 2014) and lack of qualified teachers (Hasi, 2011) still exist. Many suggestions are put forward. Methods to solve these problems are to strengthen the government leading responsibility (Xiong, 2010; Zhang, 2010), to attach great importance to the western rural preschool education (Zhang, 2011), to speed up the rural preschool education development (Zhang, 2010; Xie et al., 2014), and to implement the strategy of balanced educational development and establish urban and rural teachers exchange mechanism (Feng, 2013). The above researches provide some meaningful thoughts to solve problems about difficult admission, expensive admission and low quality of preschool in West China, but they are not totally perfect because of lack of studying on a large sample and the viewing angle of internal stakeholder orientation. Thus there is necessity to take Shaanxi Province as a sample to research these problems from the viewing angle of parents. Reasons of selecting Shaanxi Province as a sample are that it has a large population, a government valuing preschool education and researchers with strong strength to cooperate with. The main research problem is about the popularization of preschool education in Shaanxi Province, which includes difficult admission, expensive admission and low quality of preschool. The aim of this research is to know about changes taking place in Shaanxi Province after The Several Opinions on Preschool Education Development under the State Council and other laws enacted, and find out some new thoughts and methods for popularization of preschool education in Shaanxi Province and even for West China.

\section{Research Design}

\subsection{Sampling}

Shaanxi Province is taken as a sample in this research. It is in West China and had a large population of more than 37 million people and the rural population is nearly 18 million in 2014. Since Chinese Central Government announced to basically popularize preschool education in China in 2010, Shaanxi Provincial Government has issued a series of laws and regulations, including Opinions of the People's Government of Shaanxi Province on the Development of Preschool Education, Action Plan for Three Years of Pre-school Education in Shaanxi Province (2011-2013), Some Provisions on Accelerating the Development of Preschool Education. Six important measures have been put into effect, such as expanding preschool education resources, establishing a leading group for preschool, increasing financial investment, recruiting and training teachers, strengthening the management of kindergartens' access, fees and security and providing subsidies for poor children. After nearly five years' hard work, now remarkable effects have been achieved. There were 3928 kindergartens in 2010 while 6356 kindergartens in 2013. Public kindergartens accounted for 32.4\% of all sorts of kindergartens in 2014. In 2011-2013, nearly 1.20 billion ¥ was invested in preschool education and public fiscal pre-school education spending accounted for $4.82 \%$ of public financial education spending in Shaanxi Province in 2013. There are 39,965 teachers in private kindergartens and 14,134 teachers in public kindergartens while 15,749 teachers in private kindergartens and 4391 teachers in public kindergartens in 2009. Thousands of kindergarten principals and teachers received free training. The children's gross enrollment ratio of three-year preschool reached $94.64 \%$ in 2014 while $64.18 \%$ in 2010. 
In order to acquire full-scale information, three cities with different levels of economic development in Shaanxi Province have been chosen as samples. They are X City, Y City and W City. According to the official information about the levels of per capital GDP in Shaanxi Province, X City is the second highest of the ten regions in Shaanxi Province and Y City the third, W City the eighth. Different urban areas, counties and towns have been chosen from the three cities as samples. Kindergartens and parents from these kindergartens have been chosen from these different cities, urban areas, counties and towns. The details about samples are in the following Table 1 and Table 2.

\subsection{Tool}

In April 2015, Chinese Ministry of Education was eager to know how is the progress of preschool education in China after the law National Medium and Long-term Plan for Education Reform and Development (2010-2020) in China started to be implemented in 2010, so they decided to entrust some universities as a third party to evaluate the preschool education. Questionnaires were made to evaluate the progress of preschool education by authoritative experts from over ten famous Normal Universities in China and the questionnaires' reliability and validity were tested. The questionnaire used in this research is one of these questionnaires. The questionnaire consists of three parts. The first part is about basic materials. It includes background information about children and their parents, and information about selecting a kindergarten and tuition fees. The second part is the main part, which is about parents' satisfaction evaluation of preschool education. This part mainly consists of four parts: government valuing preschool education, availability, affordability and quality of preschool, which respectively include 1, 10, 6 and 23 questions. Five-point Likert scoring method is adopted in these forty questions. The third part is about parents' expectation which includes six open questions to investigate parents' expectations on preschool education.

\section{Results}

1980 questionnaires were sent out to the parents in this research and 1916 questionnaires were collected. 1777 of them are valid. Effective recovery rate is 89.75 percent. The valid questionnaires are enough for this research.

After data are collected, results about parents' satisfaction evaluation of preschool education, parents' basic materials and their expectations are as follows.

\subsection{Parents' Satisfaction Evaluation of Preschool Education}

Parents' satisfaction evaluation, of preschool education includes four parts: government valuing preschool education, availability of preschool, affordability of preschool and quality of preschool. The details about these are in the following.

\begin{tabular}{cccc}
\hline Table 1. Samples of cities, urban areas, counties and towns. \\
\hline Items & Urban area & County & Town \\
\hline X City & 1 & 1 & 1 \\
Y City & 1 & 1 & 1 \\
W City & 1 & 1 & 1 \\
Total & 3 & 3 & 3
\end{tabular}

Table 2. Samples of parents from kindergartens.

\begin{tabular}{ccccc}
\hline Items & X City & Y City & W City & Total \\
\hline Numbers of kindergarten & 26 & 23 & 17 & 66 \\
Numbers of parents & 780 & 690 & 510 & 1980 \\
\hline
\end{tabular}




\subsubsection{Parents' Satisfaction Evaluation of Government}

Government holds the key role to solve the problems about difficult admission, expensive admission and low quality of preschool. This is used to investigate whether governmental obligations are fulfilled. Valid percentage, mean score and standard deviation are given to this question by parents (Table 3).

\subsubsection{Parents' Satisfaction Evaluation of Availability of Preschool}

Availability of preschool can reflect whether problems about difficult admission are well resolved. It consists of nine questions for parents to evaluate. Mean scores and standard deviations are given in Table 4.

\subsubsection{Parents' Satisfaction Evaluation of Affordability of Preschool}

Affordability of preschool can show whether expensive admission exists and how severe it is. This can also be used to verify whether admission of a kindergarten is difficult or not. It consists of six questions and they are given to parents to evaluate. Mean scores and standard deviations are in Table 5.

\subsubsection{Parents' Satisfaction Evaluation of Quality of Preschool}

Quality of preschool is vital for children and society. It can reflect the effectiveness and level of development of preschool education. Here quality of preschool includes four parts: environment, curriculum and instruction, kindergarten teachers and home-kindergarten cooperation.

Table 3. Government valuing preschool education.

\begin{tabular}{ccccc}
\hline Items & Least satisfactory & Less satisfactory & Don’t know & More satisfactory \\
\hline Valid percentage & 2.0 & 5.8 & 11.6 & 45.5 \\
Mean & & 4.06 & 35.0 \\
Standard deviation & & 0.94 & \\
\hline
\end{tabular}

Table 4. Availability of preschool.

\begin{tabular}{|c|c|c|}
\hline Questions & Mean & Standard deviation \\
\hline Number of kindergartens & 3.80 & 0.97 \\
\hline Kindergartens for selection & 3.95 & 0.98 \\
\hline Accessibility of kindergarten & 3.97 & 1.03 \\
\hline Meeting demand of selecting a kindergarten & 4.08 & 0.93 \\
\hline Kindergarten selection of rural migrant workers' children & 4.03 & 0.94 \\
\hline Kindergarten selection of children of non-native residents & 3.96 & 0.97 \\
\hline Distance from kindergartens & 4.23 & 0.84 \\
\hline Transportation of picking up a child & 4.24 & 0.86 \\
\hline Pick up and delivery service in kindergarten & 3.98 & 1.07 \\
\hline
\end{tabular}

Table 5. Affordability to preschool.

\begin{tabular}{|c|c|c|}
\hline Questions & Mean & Standard deviation \\
\hline Tuition fees & 4.11 & 0.98 \\
\hline Charging projects & 4.31 & 0.84 \\
\hline Charge standard & 4.29 & 0.86 \\
\hline Burden of education costs & 4.20 & 0.91 \\
\hline Subsidies to low-income families & 4.17 & 0.94 \\
\hline Solutions to affordability of preschool & 4.14 & 0.93 \\
\hline
\end{tabular}




\section{Parents’ Satisfaction Evaluation of Environment of Kindergartens}

Environment provides place and support for preschool education. Quality of environment is one of the important parts of quality of preschool. Here it consists of eight problems which are used for parents to evaluate. Mean scores and standard deviations are given in Table 6.

\section{Parents' Satisfaction Evaluation of Curriculum and Instruction}

Curriculum and instruction are the core parts of quality of preschool education. Four questions are included in this part for parents to evaluate and mean scores and standard deviations are given in Table 7.

\section{Parents' Satisfaction Evaluation of Kindergarten Teachers}

Qualities and stability of kindergarten teachers and teacher-children ratio are the key parts of quality of preschool education. Six problems about qualities and stability of kindergarten teachers and teacher-children ratio are provided to parents and standard deviations are in Table 8.

\section{Parents' Satisfaction Evaluation of Home-kindergarten Cooperation}

Home-kindergarten cooperation is beneficial to the development of children. It is also important for quality of preschool. Four questions are included in this part for parents to evaluate and mean scores and standard deviations are in Table 9.

\subsubsection{Parents' Satisfaction Evaluation of Availability, Affordability and Quality of Preschool}

It is necessary to know parents' general satisfaction evaluation of availability, affordability and quality of preschool. Mean scores and standard deviations are in Table 10.

Table 6. Environment of kindergartens.

\begin{tabular}{lcc}
\hline \multicolumn{1}{c}{ Questions } & Mean & Standard deviation \\
\hline Environmental improvement & 4.33 & 0.78 \\
Capaciousness of indoor and outdoor space & 4.36 & 0.85 \\
Improvement of facilities & 4.32 & 0.83 \\
Toys activity materials increased & 4.30 & 0.84 \\
Books increased & 4.26 & 0.87 \\
Meals & 4.33 & 0.81 \\
Regular health and safety inspection & 4.37 & 0.77 \\
Security work & 4.42 & 0.72 \\
\hline
\end{tabular}

Table 7. Curriculum and instruction.

\begin{tabular}{lcc}
\hline \multicolumn{1}{c}{ Items } & Mean & Standard deviation \\
\hline Provide growth record & 4.38 & 0.78 \\
Restrain the tendency to educate children too early & 4.09 & 0.91 \\
Activities and curricula & 4.26 & 0.81 \\
Talents and Skills Show & 4.19 & 0.85 \\
\hline
\end{tabular}

Table 8. Kindergarten teachers.

\begin{tabular}{lcc}
\multicolumn{1}{c}{ Questions } & Mean & Standard deviation \\
\hline Academic background and teaching experience of principals & 4.35 & 0.77 \\
Quality of kindergarten teachers & 4.47 & 0.69 \\
Teaching enthusiasm of kindergarten teachers & 4.55 & 0.66 \\
Attitude of kindergarten teachers & 4.55 & 0.66 \\
Stability of kindergarten teachers & 4.40 & 0.76 \\
Teacher-children ratio & 4.32 & 0.82 \\
\hline
\end{tabular}


Table 9. Home-kindergarten cooperation.

\begin{tabular}{lcc}
\hline \multicolumn{1}{c}{ Problems } & Mean & Standard deviation \\
\hline Contact teachers easily when necessary & 4.56 & 0.64 \\
Contact kindergarten easily & 4.50 & 0.70 \\
Provide parenting information & 4.39 & 0.77 \\
Extending kindergarten service after school & 4.21 & 0.90 \\
\hline
\end{tabular}

Table 10. Availability, affordability and quality of preschool.

\begin{tabular}{cccc} 
& Availability & Affordability & Quality \\
\hline Mean & 4.03 & 4.22 & 4.17 \\
Standard deviation & 0.68 & 0.77 & 0.52 \\
\hline
\end{tabular}

\subsection{Parents' Satisfaction Evaluation of Preschool Education}

Parents were selected from sample kindergartens and they include fathers, mothers and grandparents. Children are 3 - 6 years old. Basic information about selecting a kindergarten were gathered because it can give supplement and verification to parents' satisfaction evaluation of preschool education. They can provide some information about availability, affordability of preschool and prove whether difficult admission and expensive admission exist. The following is about information about selecting a kindergarten and tuition fees.

\subsubsection{Selecting a Kindergarten}

Difficulties, paths and time of selecting a kindergarten can provide some useful information to prove whether difficult admission exist and know more about admission of preschool. The following three tables (Tables 11-13) are information about difficulties, paths and time of selecting a kindergarten.

\subsubsection{Tuition Fees}

Tuition fees are the most important factor to indicate whether expensive admission exists. Information about actual tuition fees and tuition fees expected is given in Table 14.

\subsection{Parents' Expectation}

Government should consider the needs, wishes and expectations of the parents in the process of policy making. Their needs, wishes and expectations can provide some useful cues for solving problems about difficult admission, expensive admission and low quality of preschool. In this part, parents express their various needs, wishes and expectations. Of all the six questions, high frequency words are chosen and their frequency of occurrence is written down in the following.

1) Great difficulties: disobedient (89), naughty (65), bad-tempered (54), capricious (51), active (31); educate (145), cultivate (47), manage (24), instruct (23), discipline (8); communicate (77), exchange ideas (19).

2) The most desired support and help that parents want to get: teacher(s) (356), faculty (3); educate (199), communicate (101), help (94), cultivate (63).

3) The most satisfying improvement parents want to get: teacher(s) (863), faculty (24); patient (164), goodhearted (107), enthusiastic (106), care for children (104); patient (164), goodhearted (107), enthusiastic (106), care for children (104).

4) The most dissatisfying aspects that parents reflect: pick-up (55), school bus (29), far (13); teacher(s) (86), faculty (2); environment (33), too many children (15), playground (13), small space (9).

5) Further improvement that parents reflect: teacher(s) (136), faculty (16); facilities (93), plaything (30), hardware (25); environment (56), classroom (13), playground (10), room (9), place (4).

6) Policies that parents expect to be implemented: subsidies (95), tuition fees (57), charges (37), investment (53), funds (6); teacher(s) (182), faculty (31); kindergarten (212), private kindergarten (59), public kindergarten (50). 
Table 11. Difficulties of selecting a kindergarten.

\begin{tabular}{cccccc}
\hline & Most difficult & More difficult & Don’t know & Easier & Easiest \\
\hline Valid percentage & 2.2 & 14.2 & 46.1 & 20.9 & 16.6 \\
Mean & & 3.36 & & \\
Standard deviation & & 0.99 & \\
\hline
\end{tabular}

Table 12. Paths of selecting a kindergarten.

\begin{tabular}{ccccc}
\hline & Interview & Ask for help & Kids and mother class in advance & Enter if sign up \\
\hline Valid percentage & 23.7 & 12.9 & 4.6 & 58.8 \\
\hline
\end{tabular}

Table 13. Time of selecting a kindergarten.

\begin{tabular}{cccccc}
\hline & Pregnancy period & Less than 1 year old & Less than 2 years old & Less than 2.5 years old & 3 years old \\
\hline Valid percentage & 4.5 & 6.4 & 18.3 & 35.6 & 35.2 \\
\hline
\end{tabular}

Table 14. Comparison between actual tuition fees and tuition fees expected per month.

\begin{tabular}{lcccc}
\hline & $\begin{array}{c}\text { Actual tuition fees }>\text { tuition fees } \\
\text { expected }\end{array}$ & $\begin{array}{c}\text { Actual tuition fees }=\text { tuition fees } \\
\text { expected }\end{array}$ & $\begin{array}{c}\text { Actual tuition fees }<\text { tuition fees } \\
\text { expected }\end{array}$ & Missed \\
\hline Percentage & 60.4 & 25.8 & 8.6 & 5.2 \\
\hline
\end{tabular}

\section{Analysis and Discussion}

Based on the above results, analysis and discussion about problems difficult admission, expensive admission and low quality of preschool are conducted.

\subsection{Parents' Satisfaction Evaluation of Preschool Education}

Whether the government attaches great importance to the development of preschool education is very important for solving the problems about difficult admission, expensive admission and low quality of preschool. It can be seen from Table 3 that evaluation value from parents in Shaanxi Province reach 4.06, and standard deviation is not out of normal conditions, which shows that parents unanimously feel more satisfactory. It shows that governments at all levels in Shaanxi Province have performed their duties well.

Availability of preschool is an important indicator to whether difficult admission exists and how severe it is. It can be seen from Table 4 that numbers of kindergartens, kindergarten selection, accessibility of kindergarten, kindergarten selection of children of non-native residents and pick up and delivery service in kindergarten scored under 4.0 and reach nearly the level of more satisfactory, while the four other indicators, namely meeting demand of selecting a kindergarten, kindergarten selection of rural migrant workers' children, distance from kindergarten and transportation of picking up a child scored over 4.0, the level of more satisfactory, and standard deviation is not out of normal conditions. It shows that difficult admission exist slightly and laws and measures governments at all levels in Shaanxi Province enacted and adopted are effective.

Affordability of preschool is also an important indicator to know about the problems about expensive admission. The data in Table 5 show that all the indicators scored over 4.0, and standard deviation is not out of normal conditions, which can declare that parents from Shaanxi Province unanimously feel more satisfactory. It can be concluded that expensive admission is not severe now and laws and measures governments at all levels in Shaanxi Province enacted and adopted are effective.

Quality of preschool education is the key indicator to weigh the development level of preschool education in Shaanxi Province. It can be seen from Table 6, Table 7, Table 8 and Table 9 that all the 22 indicators scored over 4.0, and standard deviation is not out of normal conditions, which shows that parents from Shaanxi Province unanimously feel more satisfactory. This shows that quality problems have been improved a lot in the kindergartens. Children can share preschool education with basic quality. 
From Table 10, it can reveal that as a whole, parents from Shaanxi Province unanimously feel more satisfactory with availability, affordability, and quality of preschool because each of them scored over 4.0 and standard deviation is not out of normal conditions. Great progress has been made in solving problems about difficult admission, expensive admission and low quality of preschool in Shaanxi Province.

\subsection{Supplement and Verification of Parents' Satisfaction Evaluation of Preschool}

Difficulties, paths and time of selecting a kindergarten and tuition fees can provide some supplement and verification information about admission of preschool.

In the question about difficulties of selecting a kindergarten (see Table 11), 16.6 percent of parents think it easiest, 20.9 percent easier, 46.1 percent answer “Don’t know”, 14.2 percent more difficult and 2.2 percent most difficult. The mean of difficulties scored 3.36 and standard deviation is 0.99 . All this shows that selecting a kindergarten for a parent is not difficult. This also indicates admission of a kindergarten is not very difficult.

In Table 12, paths of selecting a kindergarten can be seen. 58.8 percent of parents state that their children can enter a kindergarten if sign up, 23.7 percent of parents think that their children enter a kindergarten by interviewing, 12.9 percent by asking for help, 4.6 percent by going to Kids and Mum Class in advance. From these facts we can conclude that admission of a kindergarten is not very difficult.

Time of selecting a kindergarten is an important indicator to indicate the fierce competition level of selecting a kindergarten. Data from Table 13 show that 70.8 percent of parents decide to select a kindergarten for their children when they are 2 - 3 years old. This demonstrates that selecting a kindergarten in Shaanxi Province is not difficult and admission of a kindergarten is not very difficult.

Tuition fees affect admission of a kindergarten a lot. It can be concluded from Table 14 that 60.4 percent of parents paid more actual tuition fees than tuition fees expected per month. Only 8.6 percent of parents paid fewer tuition fees than tuition fees expected per month. Data from Table 14 shows that most of parents in Shaanxi Province think tuition fees expensive. It seems that expensive admission is not well solved. More efforts should be intensified to solve this problem.

\subsection{Parents' Expectation}

This part shows parents' needs, wishes and expectations. It can be seen from high frequency words and their frequency of occurrence that the greatest difficulties parents are facing are that they can't understand children's characteristics of physiological and mental development and many of them don't know how to educate their children and communicate with them. Because of these reasons, parents in Shaanxi Province are eager to get support and help from teachers and kindergartens and learn to how to educate and instruct their children.

Great changes have taken place since Chinese Central government and Shaanxi Provincial Government enacted many laws and regulations. Parents in Shaanxi Province think that the most satisfying aspects in kindergartens are the increasing numbers of teachers, quality of faculties and environment of kindergartens. Though many effective measures have been taken to boost the development of kindergartens, dissatisfying aspects still exist. Parents point out that the most dissatisfying aspects are picking up and delivery service, quality of environment, quantity and quality of faculties in kindergartens.

For the future improvement, parents hope to improve quantity and quality of faculties and environment. For the future policies, parents expect that Chinese Central government and governments at all levels in Shaanxi Province can increase input to build more public kindergartens, give more subsidies to the poor children, recruit more teachers and provide qualified teachers.

\section{Conclusions and Suggestions}

From the investigation of parents' satisfaction evaluation of preschool education in Shaanxi Province, conclusions can be made that parents are more satisfactory with the progress of popularization of preschool education in West China as a whole. The problem about difficult admission of preschool has been eased preliminarily. Much progress has been made in solving the problem about expensive admission. Quality of preschool has been improved significantly. According to the parents' needs, wishes and expectations and the actual situation of West China, on the future policy formulation and implementation, Chinese Central Government and governments at all levels in West China should focus on expanding preschool education resources, adjusting the struc- 
ture of private kindergartens and public kindergartens, improving the fund input mechanism, advancing the quality of kindergartens and enhancing home-kindergarten cooperation.

\section{Acknowledgements}

We want to give our best thanks to the experts permitting us to use the questionnaires, data and materials. We also sincerely thank Dr. Kongchao He and Dr. Shan'an Wang for their important advice. We want to thank Jiajia Wang for her technical support.

\section{Fund}

Research project grants: Comparative Study of Preschool Teachers between China and America (Project Number: 12YJA880091). Humanities and Social Sciences of Chinese Ministry of Education Planning Fund.

\section{References}

Chinas State Council (2010a). National Medium and Long-Term Plan for Education Reform and Development (2010-2020). (In Chinese) http://www.china.com.cn/policy/txt/2010-03/01/content 19492625 3.htm

Chinas State Council (2010b). The Several Opinions on Preschool Education Development under the State Council. (In Chinese) http://www.gov.cn/zwgk/2010-11/24/content_1752377.htm

Chinese Ministry of Education (2014). The Second Phase of the Preschool Education in Shaanxi Three Years Action Plan (2014-2016). (In Chinese) http://www.snedu.gov.cn/news/qitawenjian/201411/05/8531.html

Feng, F. (2013). On the Status of the Equipment of Preschool Teachers from the Perspective of the Balanced Development of Education. Master's Dissertation, Chongqing: Southwest University, Dissertation Abstract: 1.

Hasi, Q. (2011). The Investigation of Preschool Education in Remote Pastoral Areas of Middle-Eastern Inner Mongolia in Education Fairness. Master’s Dissertation, Hohhot: Inner Mongolia Normal University, Dissertation Abstract: 2.

Hu, M. (2011). Research on Predicaments and Countermeasures of Preschool-Classes’ Development in Impoverished Rural Areas in Gansu Province. Master's Dissertation, Chongqing: Southwest University, Dissertation Abstract: 1.

Jiang, W. W. (2013). Research on Existing Problems of Popularizing Preschool Education in Rural Areas of West China. Master's Dissertation, Chongqing: Southwest University, Dissertation Abstract: 1.

Xia, S. H. (2014). On the National Poverty County’s Efficiency of the Three Years Project of Preschool Education in Chongqing Municipality. Master’s Dissertation, Chongqing: Southwest University, Dissertation Abstract: 1.

Xie, Y. K. et al. (2014). On the Bottleneck and Breakthrough in the Development of Rural Preschool Education in the Minority Area of Southwest China. Studies in Preschool Education, 4, 58.

Xiong C. C., \& Zhang, F. (2010). Thinking Clearly, Strengthening Responsibility and Striving to Achieve Leapfrog Development of Preschool Education. Studies in Preschool Education, 8, 16.

Zhang, X. L. (2013). Taking the Lead in Actualizing the Preschool Compulsory Education Policy in Western Minority Areas (Dissertation Abstract: p. 1). Master’s Dissertation, Chengdu: Southwest Jiaotong University.

Zhang, Y. P. (2011). Discussion Policy Path on Preschool Education of Western Countryside Areas from the Perspective of Public Policy. Master's Dissertation, Yan’an: Yan'an University, Dissertation Abstract: 1. 